set-screws to any microscope with the ordinary horse-shoe base so that the instrument, while not attached in any manner to the microscope, can be brought instantly into accurate alignment with it; $(2)$ a supporting rod $(B)$ carrying a collar $(C)$ and clamp $(D)$, the latter of which is specially constructed for holding a round horizontal arm $(E)$ in a manner that will permit its being turned at any angle and yet held with great firmness without turning; and $(3)$ the camera $(F)$ carried by tle horizontal arm, by means of which it may be adjusted to any position from vertical to horizontal or tipped at any desired angle.

The camera itself takes the ordinary plate-holder for $31 / 4$ by $41 / 1$ plates, but is heavily reinforced in its working parts and has an unusualiy long bellows. A shutter $(G)$ and light-tight sleeve $(H)$ are attached to the front board. In use, the microscope to which the camera has been previously adjusted and to which is permanently affixed only a small inconspicuous part $(I)$ of the light-tight sleeve may be used anywhere on a fairly level table. When a desirable field is found, the entire stand and camera are moved into position so that the studs and set-screws are in contact with the base of the microscope, when it will be found that the two instru-

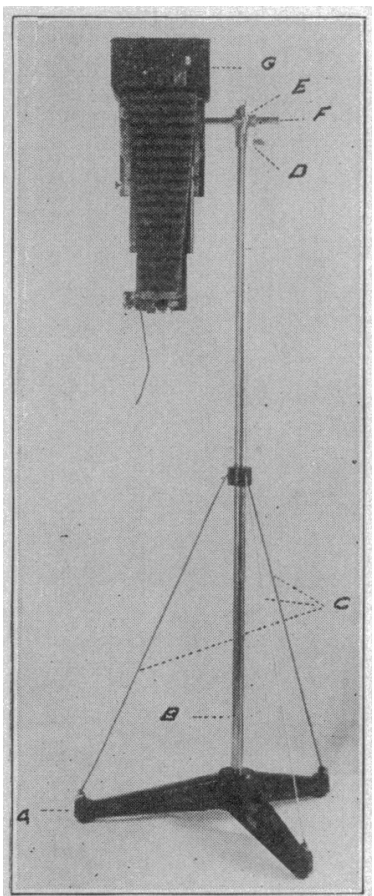

Fig. "4.-Large stand and camera for specimen and general laboratory photog raphy; $A$, base; $B$, support
rcd; $C$, guy rods $: D$, collar $\underset{E,}{\mathrm{rcd} ;} \boldsymbol{C}$, guy rods ; $D$, collar; arm $: G$, camera. inents are in exact alignment. The readjustment of the focus may be made ordinarily with low powers by the fine adjustment screw, or, if necessary, with high powers, by refocusing on the ground glass. The subsequent steps of taking the photograph are those ordinarily employed.

The camera may be rotated on the support-rod at will and brought again into exact alignment by means of two stopstuds-one on the collar and one on the clamp-which engage with each other. It may be used with the microscope in the horizontal position or inclined at any angle, though the instantaneous alignment is obtained only when the instrument is in the vertical position.

Photographic lenses may be added to the shutter and the camera very conveniently used for photography of specimens and apparatus, or for making portraits, ete., while it is stil attached to the stand. Or the camera may be detached entirely from the stand and then forms a high-class folding pocket camera suitable for plates or film-pack. For use with extra long-focus lenses, I have had this camera built with a 16-inch extension which is obtained by means of a supplementary bed.

IV. LARGe STAND AND CaMERA For PORTRAITs, GRoss SPECIMENS AND GENERAL LABORATORY WORK

Six years aro Andrews and I built and described (Jour. Med. Research, 1908, xvii, 487) a large stand and camera for photographing pathologic specimens submerged. This apparatus has proved to be thoroughly satisfactory in our hands, but there is a demand for a more portable and withal a less expensive machine to serve the same purpose. I have therefore devised the stand and camera shown in Figure 4. This apparatus which is well adapted for taking portraits of patients, photographs of gross specimens or operations and for general photographic laboratory work, consists of a heavy tripod base $(A)$ into which is screwed a heavy support-rod $(B)$ 5 feet high, which is reinforced and made more rigid by three small guy-rods $(C)$ running from a collar near its middle point to the ends of the feet of the tripod. On the supportrod are carried a collar $(D)$ and right-angle clamp $(E)$ which is specially bored to hold securely at any angle a round arm $(F)$ with a forked end to which is attached an ordinary long-extension 5 by 7 folding box camera $(G)$. The eamera may 'be used in the vertical position, as when photographing specimens under water, horizontally as for portrait work, or inclined at any angle as in taking photographs of operations, apparatus, etc. Hardened steel domes are inserted at the bearing points of the tripod in lieu of the usually unsteady casters. The whole apparatus is portable, light, simple in construction and extremely rigid, while its cost is very low.

\section{A MEANS OF FACILITATING THE APPLICATION OF LEG-DRESSINGS}

John Staige Davis, M.D., Baltimore

Instructor in Surgery, Johns Hopkins Lniversity Medical Department

An uncomfortable or awkward position hinders efficient work in any occupation, including surgical manipulations. In the outpatient department of every large surgical service many leg cases are dressed. Such dressings are often avoided, partly because of the physical discomfort necessary in applying these dressings under ordinary conditions.

The heel-rest usually supplied for this work is slightly higher than the seat of an ordinary chair, and unless the dresser sits down to apply the bandage, he is compelled to bend over and assume a very tiring position, which is a matter of considerable moment where there are a number of these dressings.

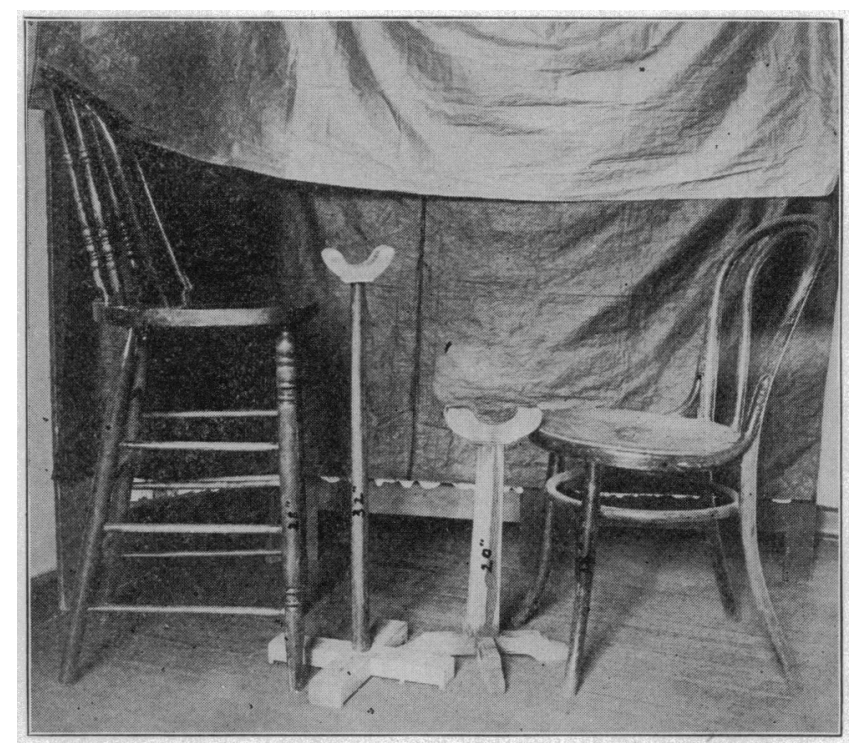

The high chair and heel-rest compared with those ordinarlly used.

In a busy clinic it is obviously impractieable for each dresser to have a seat for this purpose, and consequently a considerable amount of energy is unnecessarily expended. In order to avoid this useless fatigue and to accelerate the work, it occurred to me that higher chairs and correspondingly higher heel-rests might be of advantage. A number of these chairs with seats 28 inches above the floor, and heel-rests 32 inches high, were tried in one of the rooms of the outpatient department, and their use has greatly facilitated the application of leg-dressings.

Dressings on other parts of the body are also made easier by the use of these chairs, thus sparing the surgeon unnecessary discomfort. Should it be desirable to have the leg elevated before applying the dressing, the high heel-rest may be used while the patient sits on a chair of ordinary height

These simple and inexpensive modifications in the equipment of a surgical dressing-room seemed worth while reporting, as I have found them most satisfactory.

Women in Medicine.-We are prone in the modern time to think that our generation is the first to offer to women any facilities or opportunities for education in medicine. We are prone, however, just in the same way, to consider that a number of things that we are doing are now being done for the first time. As a matter of fact, it is extremely diffcult to find any important movement or occupation that is not merely a repetition of a previous interest of mankind.Walsh: Makers of Medicine. 